\title{
PROPERTIES OF THE INTERMEDIATE POINT FROM THE TAYLOR'S THEOREM
}

\section{DOREL I. DUCA}

Abstract. If $I \subseteq \mathbb{R}$ is an interval, $a \in I$ and $f: I \rightarrow \mathbb{R}$ is $n \geqslant 1$ times differentiable on $I$, then, in view of Taylor's theorem, there exists a function $\bar{c}: I \rightarrow I$ such that, for each $x \in I$,

$$
f(x)=\sum_{k=0}^{n-1} \frac{f^{(k)}(a)}{k !}(x-a)^{k}+\frac{f^{(n)}(\bar{c}(x))}{n !}(x-a)^{n} .
$$

In this paper we study the behaviour of the derivatives $\bar{c}^{(p)}$ and $\bar{\theta}^{(p)}$ of the functions $\bar{c}$ and $\bar{\theta}$, respectively, when $x$ approaches $a$, where $\bar{\theta}: I \rightarrow] 0,1[$ is defined by $\bar{\theta}(x)=(c(x)-a) /(x-a)$, if $x \in I \backslash\{a\}$ and $\bar{\theta}(a)=1 /(n+1)$.

Mathematics subject classification (2000): 26A24.

Keywords and phrases: Taylor's theorem, intermediate point, mean-value theorem.

\section{REFERENCES}

[1] U. Abel And M. Ivan, The Differential Mean Value of Divided Differences, J. Math. Anal. Appl., 325 (2007), 560-570.

[2] H. Amann And J. Escher, Analysis, Birkhauser Verlag, Basel-Boston-Berlin, I (1998), II (1999), III (2001).

[3] D. Andrica, D.I. Duca, I. Purdea And I. Pop, Basic Mathematics (in romanian), Studium Publishing House, Cluj-Napoca, 2004.

[4] D. AZAgra, J. GomeZ and J.A. Jaramillo, Rolle's Theorem and Negligibility of Points in Infinite Dimensional Banach Spaces, Journal of Mathematical Analysis and Applications, 213 (1997), $487-$ 495.

[5] A.G. AzPeitia, On the Lagrange Remainder of the Taylor Formula, The American Mathematical Monthly, 89 (1982), 311-312.

[6] D.I. DucA, A Note on the Mean Value Theorem, Didactica Mathematica, 19 (2003), 91-102.

[7] D.I. Duca And O.T. Pop, Concerning the Intermediate Point in the Mean Value Theorem, Math. Inequal. Appl., 12, 3 (2009), 499-512

[8] D.I. DuCA AND O. Pop, On the Intermediate Point in Cauchy's Mean-Value Theorem, Math. Inequal. Appl., 9, 3 (2006), 375-389.

[9] M. Furi AND M. MARTELli, On the Mean Value Theorem, Inequality, and Inclusion, The American Mathematical Monthly, 98, 9 (1991), 840-846.

[10] Grandshteyn, I.S. And Ryzhik, I.M., Table of Integrals, Series and Products, Academic Press, NY, 1980.

[11] R. Mera, On the Determination of the Intermediate Point in Taylor's Theorem, The American Mathematical Monthly, 99, 1 (1992), 56-58.

[12] I. Pawlikows Ka, An Extension of a Theorem of Flett, Demonstratio Math., 32 (1999), 281-286.

[13] J.P. PENot, Mean-Value Theorem with Small Subdifferentials, Journal of Optimization Theory and Applications, 94, 1 (1997), 209-221.

[14] W. Rudin, Real and Complex Analysis, third edition, McGraw Hill, New York, 1987.

[15] E. SCHEChTER, Handbook of Analysis and its Foundations, Academic Press, San Diego, 1997. 
[16] T. TRIF, Asymptotic Behavior of Intermediate Points in certain Mean Value Theorems, Journal of Mathematical Inequalities, 2, 2 (2008), 151-161. 